\title{
DETERMINATION OF STRENGTH FOR RELIABILITY ANALYSIS MULTILAYER CERAMIC CAPACITORS
}

Kristin Breder, Andrew A. Wereszczak, Laura Riester, Timothy P. Kirkland, and Ralph J. Bridge

High Temperature Materials Laboratory

Oak Ridge National Laboratory, Oak Ridge, TN 37831.

\begin{abstract}
A Nanoindenter ${ }^{\mathrm{TM}}$ equipped with a Vickers indenter was used to measure fracture toughness of Multilayer Capacitors (MLCs) and $\mathrm{BaTiO}_{3}$ blanks. Strength of blanks of $6.3 \times 4.7 \times 1.1 \mathrm{~mm}^{3}$ was measured by performing three-point flexure using a $4 \mathrm{~mm}$ support span. The size of the strength limiting pores in the flexure tests was compared to pore sizes measured on polished MLC cross sections, and it was found that much larger pores were present in the 3-point flexure specimens. Strength distributions for the MLCs were generated using the measured fracture toughness values, assuming the measured pores or second phase inclusions were strength limiting.
\end{abstract}

\section{INTRODUCTION}

Performing reliability analysis for multilayer ceramic capacitors (MLCs) is of importance in improving failure rates of existing designs, but especially in regard to new designs. There is a drive to produce MLCs with maximum charge capacity, which can be achieved by using minimal dielectric layer thickness $(4 \mu \mathrm{m}$ or smaller). However, uncertainty exists over whether new failure modes will result as these layers continue to reduce in thickness. Building on experience gained from reliability analysis of structural ceramics, computer algorithms have been coupled with finite element analysis (FEA) to perform reliability analysis of MLCs. ${ }^{1-3}$ Major inputs to these codes are strength distributions as well as fracture modes and fracture criteria. For structural components it has been demonstrated that there may be problems in generating strength data that are representative for the component under consideration. For example, standard flexure or tensile test specimens are typically smaller than the components, they are of a different shape, and may be manufactured in a different manner; consequently, the flaw population between component and specimen can be different. Much work has been done to overcome

" Research sponsored by the U.S. Department of Energy, Assistant Secretary for Energy Efficiency and Renewable Energy, Office of Transportation Technologies, as part of the Advanced Automotive Materials Program, under Contract DE-AC05-96OR22464, managed by Lockheed Martin Energy Research Corporation. 


\section{DISCLAIMER}

This report was prepared as an account of work sponsored by an agency of the United States Government. Neither the United States Government nor any agency thereof, nor any of their employees, make any warranty, express or implied, or assumes any legal liability or responsibility for the accuracy, completeness, or usefuiness of any information, apparatus, product, or process disclosed, or represents that its use would not infringe privately owned rights. Reference herein to any specific commercial product, process, or service by trade name, trademark, manufacturer, or otherwise does not necessarily constitute or imply its endorsement, recommendation, or favoring by the United States Government or any agency thereof. The views and opinions of authors expressed herein do not necessarily state or reflect those of the United States Government or any agency thereof. 


\section{DISCLAIMER}

Portions of this document may be illegible in electronic image products. Images are produced from the best available original document. 
this, e.g., making specimens from components and controlling machining parameters, which have made life predictions more reliable. For small ceramic components such as MLCs and other electronic ceramics, the problem essentially is the opposite; namely, using standard specimens to generate strength data to predict the behaviour of components that are very much smaller than the test specimens. In this case the material processing issues may be even more pronounced. As material volumes get very small the microstructure may change, and the properties may be different from the same material processed into larger volumes.

In a previous paper ${ }^{1}$ we have demonstrated that it is possible to use life prediction codes to perform reliability analysis of MLCs. In the present paper we will discuss some of the issues regarding determining the strength data that will serve as one of the input parameters in the analysis.

\section{EXPERIMENTAL PROCEDURE}

MLCs from three different manufacturers have been tested. These were nominally the same type; X7R $08050.1 \mu \mathrm{F}$ and typically $4 \times 2 \times 1 \mathrm{~mm}^{3}$ in size with alternating layers of $\mathrm{BaTiO}_{3}$ dielectric and silver/palladium electrodes. The capacitors were sectioned in three orthogonal planes and polished. Two types of $\mathrm{BaTiO}_{3}$ blanks were acquired for comparisons; $25 \mathrm{~mm}$ diameter and $3 \mathrm{~mm}$ thick sintered discs and small flexure specimens with nominal dimensions of $6.3 \times 4.7 \times 1.1 \mathrm{~mm}^{3}$ produced in a similar way as the dielectric by one of the manufacturers. These had a grain size of less than $1 \mu \mathrm{m}$, and had been tumble polished to bevel the edges.

Polished surfaces were produced for each of the 5 specimen types, and a Nanoindenter ${ }^{\mathrm{TM}}$ equipped with a Vickers indenter was used to determine the fracture toughness $\mathrm{K}_{\mathrm{IC}}$. The hardness and elastic modulus were determined in standard fashion using a Berkovich indenter in the continuous stiffness mode. ${ }^{4}$ The fracture toughness was determined using: ${ }^{5}$

$$
K_{I C}=\alpha\left(\frac{E}{H}\right)^{1 / 2} \frac{P}{C^{3 / 2}}
$$

where $\mathrm{E}$ is the elastic modulus, $\mathrm{H}$ the hardness, $\mathrm{P}$ the indentation load, $\mathrm{C}$ the crack length, and $\alpha=0.016$ is an empirical constant representing the intensity of the stress field around the indenter. The Nanoindenter has not frequently been used for this type of toughness measurements, primarily because most materials will not crack when indented at these ultra low loads. Previously, a cube cornered indenter has been used because this produces a more intense stress field and hence, may more easily produce cracks; however, cracks in $\mathrm{BaTiO}_{3}$ could readily be induced at a load down to $50 \mathrm{mN}$. The value of $\alpha$ as given in Eq. (1) was found using Vickers indenter at a higher load range ${ }^{5}$, and its applicability to the low load range is dependent on the shape of the indenter, i.e. its sharpness. The load to area ratio of the Vickers indenter was determined and self similar indents were produced for the load range applied here $(50-300 \mathrm{mN})$. Comparisons have also been made between "NanoVickers" and "MicroVickers" and it was found that the intensity of the stress fields was similar..$^{6-8}$ A standard Vickers hardness tester was used for comparison. 
The cracks were measured using a scanning electron microscope (SEM) for the nanoindents, and an optical microscope for the microindents.

Strength was measured for the small flexure bars in 3-point flexure. The fixture had a span of $4 \mathrm{~mm}$ and had support pins that were free to roll. Beyond the experimental difficulties of testing on such a small scale, there is a concern that friction and other sources of errors may contribute in an unproportionally large amount, so an analysis of the error sources was performed. ${ }^{9,10}$ This analysis showed that the friction problem may be the largest error, and that rolling pins are essential to offset this. Other error sources were determined to be quite small, however, the analysis further showed that the errors will rapidly increase if the support span is reduced for the given specimen thickness. The cross-head displacement rate was $0.5 \mathrm{~mm} / \mathrm{min}$ and the testing was performed in ambient air. The two-parameter Weibull strength distribution was determined for the 3-point flexure strength data using AlliedSignal's CERAMIC code. ${ }^{3}$ The code uses the maximum likelihood method for determining the Weibull modulus $m$ and the scaling parameter $\sigma_{0}$. Fractography was performed using optical and scanning electron microscopes. Different strength distributions were explored by comparing the strength limiting flaws (pores) found in the 3-point flexure specimens to the pores and inclusions found in the polished cross sections.

\section{RESULTS AND DISCUSSION}

Figure 1 shows part of a polished cross section of a MLC. Barely seen in this figure are three rows of Nanoindents bracketed by arrows. By comparison, a regular Vickers indent would typically have an impression diameter of more than $50 \mu \mathrm{m}$ and hence, sample several layers.

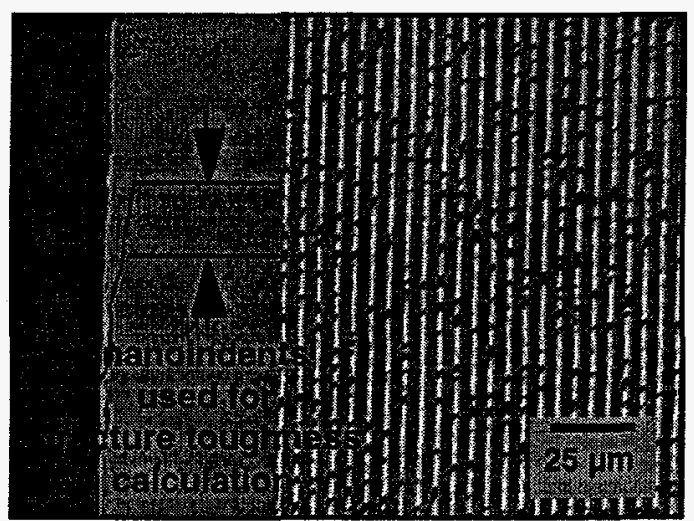

Fig. 1. Cross section of a typical MLC.

Figure 2 shows two Vickers indents produced in a capacitor showing that in order to produce well-defined cracks the indents had to be placed in the outer margin of the MLC which had a thickness of about $100 \mu \mathrm{m}$ The indent in Fig. 2 a) is from the margin area away from the end caps, and the well defined indent and equal length of all four cracks indicated that this was an area with appropriately low or uniform residual stresses. The indent in Fig. 2 b) is from the 
dielectric with electrode material on both sides, and it can be seen that this indent is too large to be used for determination of the material properties.
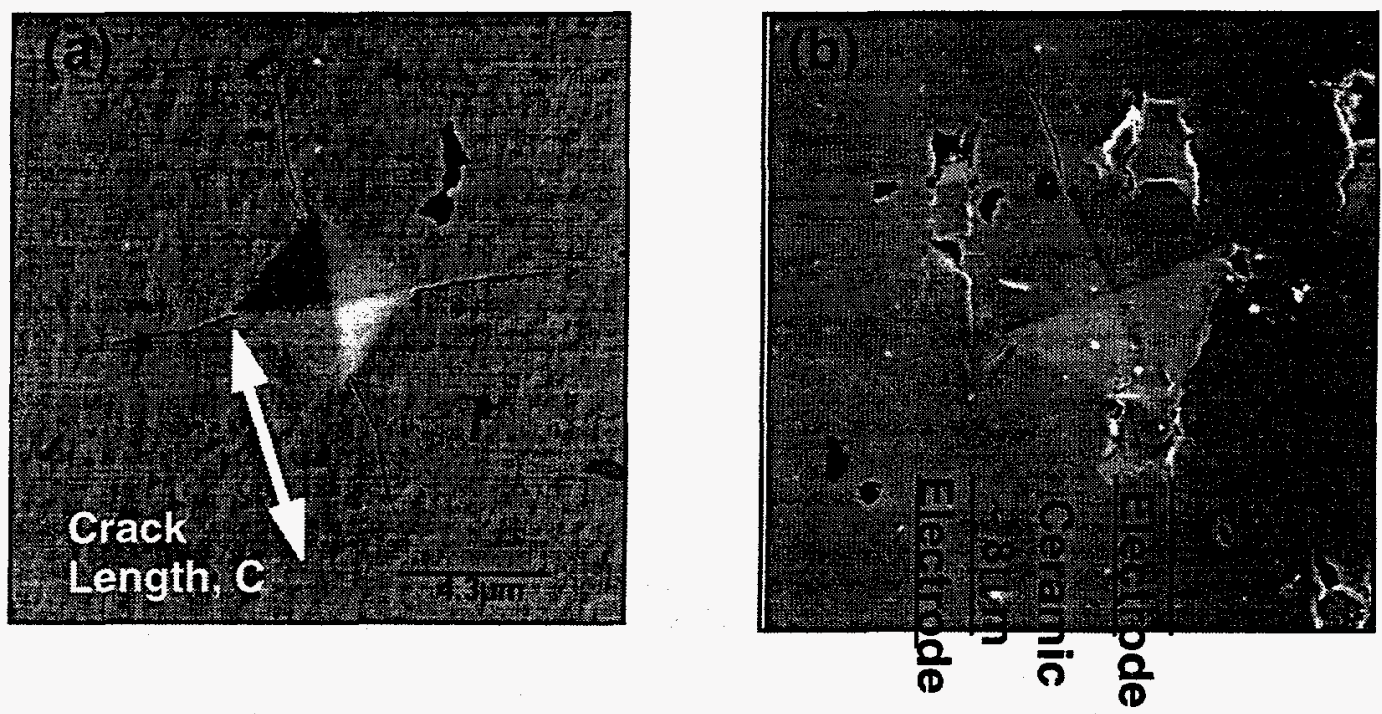

Fig. 2. a) Typical Vickers indent produced by the Nanoindenter in the dielectric margin of the MLC. b) A Vickers indent produced by the Nanoindenter in the dielectric layer covered both ceramic and metal electrode layers.

Table I gives the results of fracture toughness measured for the five dielectric materials. All values are well within ranges reported for similar materials." It can be seen that the toughness of the sintered blanks was significantly lower than for the other materials. This material had a porous microstructure and larger grain size than the other materials, and it was concluded that this was not representative for the material in the capacitors. Freiman ${ }^{11}$ states that internal stresses due to the phase transformation in these materials have manifested themselves in deviation from the indentation model at small indentation loads. The toughness measured here does not seem to indicate this, however, caution must be exercised when interpreting data obtained at these very low indentation loads. Similarly, residual stress effects from the manufacture of the capacitors may influence the data, although the very even cracks indicated no significant stress gradients or different stress states. It is also important to note that the fracture toughness values obtained by "NanoVickers" and "MicroVickers" were essentially the same for the blanks, and that the toughness values for the 3-point bend specimens were the same as for capacitor B made by the same manufacturer.

Figure 3. shows the results of the 3-point flexure testing. The Weibull characteristic strength was $104 \mathrm{MPa}$ and the Weibull modulus was 10.8 . This is a strength level comparable to other reports for similar material. " Fractography showed that failure was predominantly from relatively large pores. Assuming these were Griffith type flaws, the pore radius would be of the order of $90 \mu \mathrm{m}$. Using these data for input into reliability analysis of the MLC would pose an obvious problem: pores of that size would not exist in the dielectric of a normal capacitor 
whose dielectric layer was one order of magnitude smaller. The marginal area was thicker as shown above, but it was not thought that this would be a representative strength distribution for the dielectric.

Cross sectioned and polished capacitors were imaged in the SEM, and it was observed that the pores were indeed very much smaller, see Fig. 4. In addition to the pores, inclusions of a second phase were also noted in the MLCs.

Table I. Fracture toughness measured by indentation

\begin{tabular}{|l|c|c|}
\hline & $\begin{array}{c}\mathrm{K}_{\mathrm{IC}} \text { Measured by } \\
\text { Nanoindentation } \\
\text { with Vickers } \\
\text { Indenter }\end{array}$ & $\begin{array}{c}\mathrm{K}_{\mathrm{IC}} \text { Measured by } \\
\text { Standard Vickers } \\
\text { Indentation }\end{array}$ \\
\hline BaTiO $_{3}$ Blanks & $0.79( \pm 0.08)$ & $0.71( \pm 0.03)$ \\
\hline $\begin{array}{l}\text { BaTiO } 3 \text { 3-Point } \\
\text { (“Capacitor B") }\end{array}$ & $1.12( \pm 0.14)$ & \\
\hline Capacitor A & $1.36( \pm 0.29)$ & \\
\hline Capacitor B & $1.11( \pm 0.28)$ & \\
\hline Capacitor C & $1.53( \pm 0.47)$ & \\
\hline
\end{tabular}

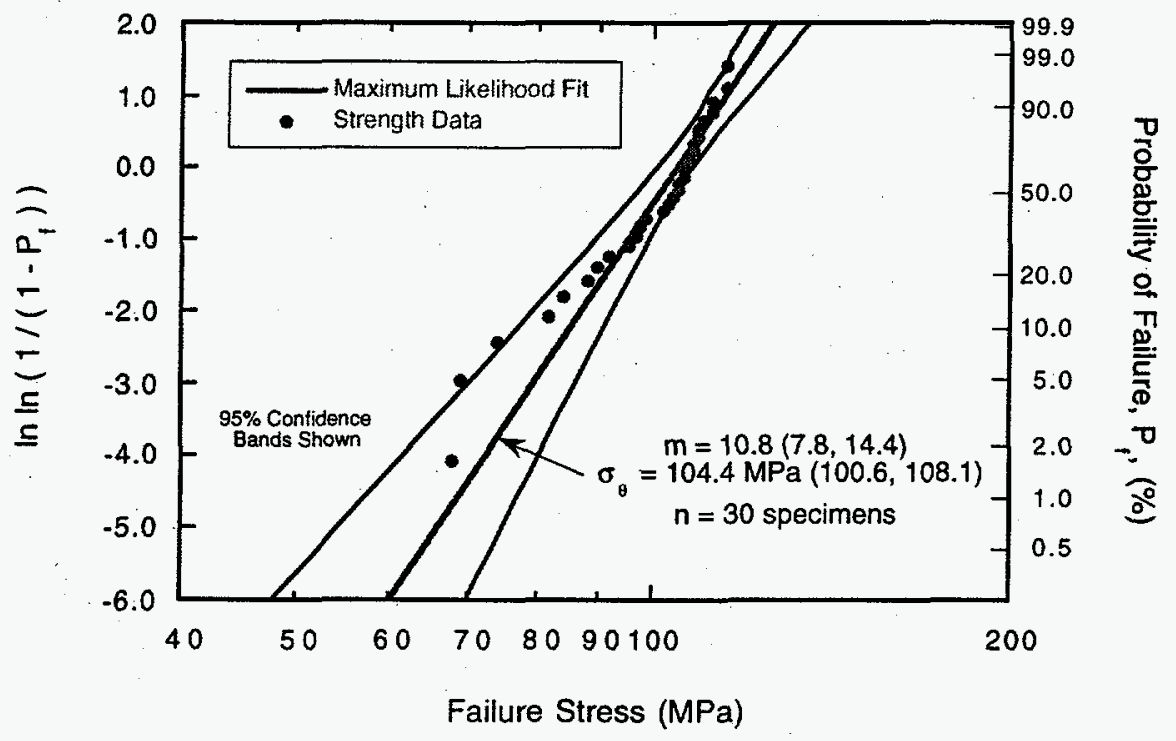

Fig. 3. Weibull analysis of three-point flexure data. Values in parentheses constitute $\pm 95 \%$ confidence estimates. 


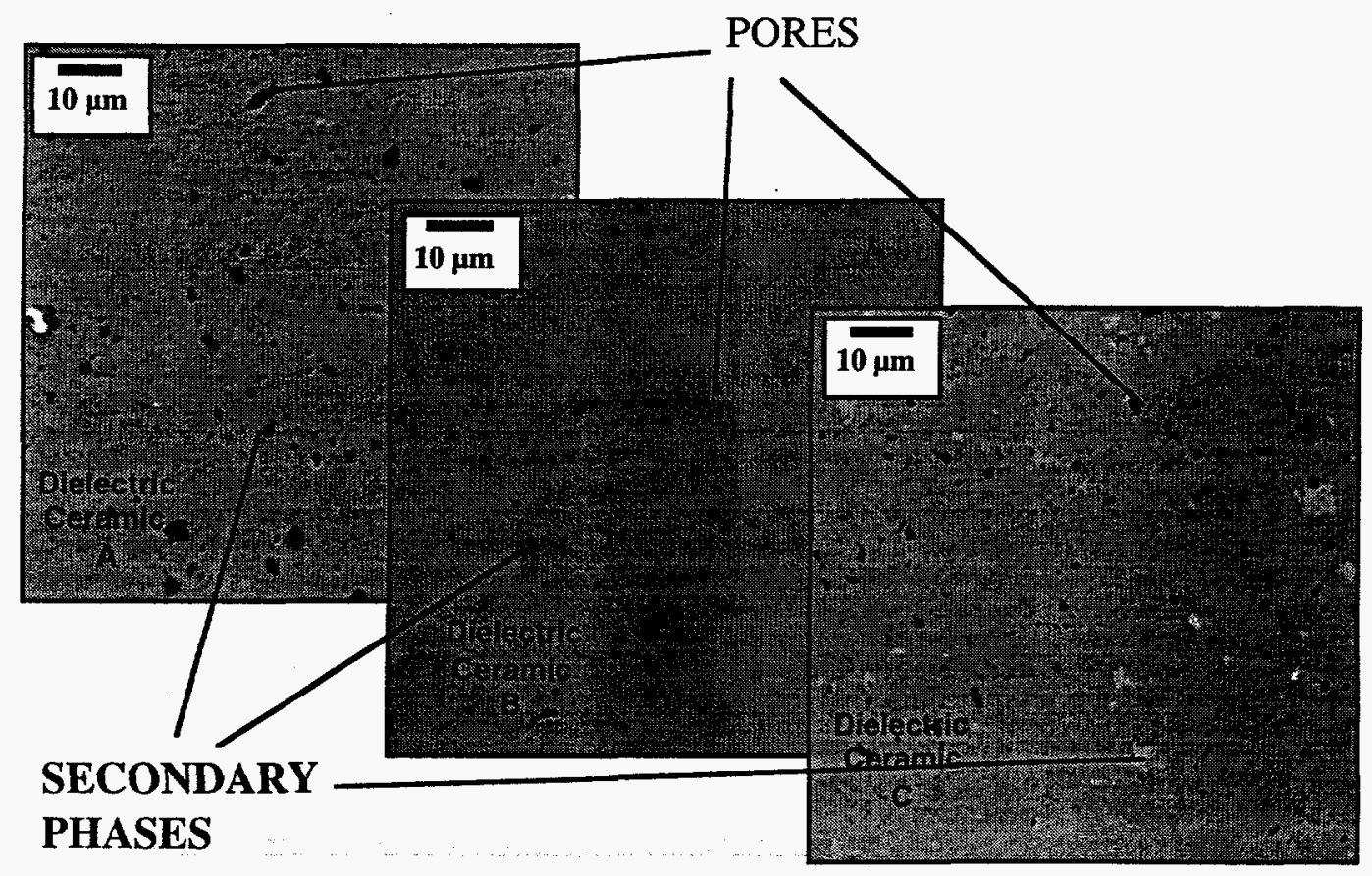

Fig. 4. Comparison of typical microstructures of three MLCs of nominally the same type.

Working under the assumption that these pores or the second phase inclusions possibly would be the strength limiting flaws, the size distributions were quantified using an image digitizing program. The strength of the material containing these pores or inclusions was calculated assuming they were Griffith type flaws (ignoring the difference between pores and second phase as fracture initiating flaws), using the fracture toughness measured for the particular dielectric material. These strength values were then fitted to a two parameter Weibull distribution as done for the 3-point flexural strength data. To facilitate the comparison of these distributions for the three MLC sets and the 3-point flexure strength set, the distributions were scaled to a unit volume (i.e., $V=1 \mathrm{~mm}^{3}$ ) and then graphed assuming a uniaxial application of tensile stress for each material. The results are shown in Figs. 5 and 6, where the results from the 3-point flexure test have been scaled to the same volume for comparison.

As can be seen, the predicted strengths were higher than that measured in 3-point flexure, as one would expect from the differences in pore sizes. It is further seen that it could be possible that the second phase inclusions rather than the pores would be strength limiting in the capacitors. The indentation experiments induced cracks of the same order of magnitude as the pores and second phase inclusions, and similar strength distributions would be obtained if these types of cracks were strength determining. 


\section{SUMMARY AND CONCLUSIONS}

Using a Nanoindenter ${ }^{\mathrm{TM}}$ equipped with a Vickers indenter it was possible to measure the fracture toughness of MLCs in situ. The fracture toughness obtained corresponded well with fracture toughness obtained using a "MicroVickers" indenter at loads an order of magnitude higher. The fracture toughness of small flexure specimens produced by the same method as MLCs compared well to the corresponding dielectric material. Strengths determined by 3-point flexure corresponded well to strengths obtained for similar materials, however, it was found that the strength limiting pores in the flexure specimens were substantially larger than pores measured in the dielectric material. Polished cross sections of the MLCs revealed the existence of pores and second phase inclusions, and strength distributions were obtained assuming those would be strength limiting using the measured fracture toughness. The strengths obtained in this fashion were higher than those measured in 3-point flexure, corresponding to the different sizes in strength limiting flaws.

\section{REFERENCES}

1. A. A. Wereszczak, K. Breder, M. K. Ferber, R. J. Bridge, L. Riester, and T. P. Kirkland, "Failure Probability Prediction of Dielectric Ceramics in Multilayer Capacitors," Transactions of the American Ceramic Society, In Press, 1999.

2. N. N. Nemeth, J. M. Manderscheid, and J. P. Gyekenyesi, "Ceramic Analysis and Reliability Evaluation of Structures (CARES), Users and Programmers Manual," Report TP-2916, National Aeoronautics and Space Administration, 1990.

3. "Life Prediction Methodology for Ceramic Components of Advanced Heat Engines, Phase 1," Prepared by AlliedSignal Engines, Phoenix, AZ, ORNL/Sub/89-SC674/1-2, DOE Office of Transportation Technologies, 1995.

4. W. C. Oliver and G. M. Pharr, "An Improved Technique for Determining Hardness and Elastic Modulus Using Load and Displacement Sensing Indentation Experiments," J. Mater. Res., 7 1564-83 (1992).

5. G. R. Anstis, P. Chantikul, B. R. Lawn, and D. B. Marshall, "A Critical Evaluation of Indentation Techniques for Measuring Fracture Toughness: I, Direct Crack Measurements," J. Am. Cer. Soc., 64 533-538 (1981).

6. G. M. Pharr, D. S. Harding, and W. C. Oliver, "Measurement of Fracture Toughness in Thin Films and Small Volumes Using Nanoindentation Methods," Proc. NATO Advanced Study Institute on Mechanical Properties and Deformation Behavior of Materials Having Ultrafine Microstructures, edited by M. Nastasi, 1992.

7. D. S. Harding, and W. C. Oliver, and G. M. Pharr, "Cracking During Nanoindentation and its Use in the Measurement of Fracture Toughness," Mater. Res. Soc. Symp. Proc., 356, 663, 1995.

8. L. Riester, Unpublished work, 1998. 
9. F. I. Baratta, W. T. Matthews, and G. D. Quinn, "Errors Associated with Flexure Testing of Brittle Materials," U.S. Army Materials Technology Laboratory, Report MTL TR 87-35, Watertown, Ma, 1987.

10. T. Lube, M. Manner, and R. Danzer, "The Miniaturization of the 4-PointBend Test," Fatigue \& Fract. Engng. Mater. Struct, [11] 20 1605-16, 1997.

11. S. W. Freiman and R. C. Pohanka, "Review of Mechanically Related Failures of Ceramic Capacitors and Capacitor Materials," J. Am. Ceram. Soc., 72 [12] 2258-63 1989.

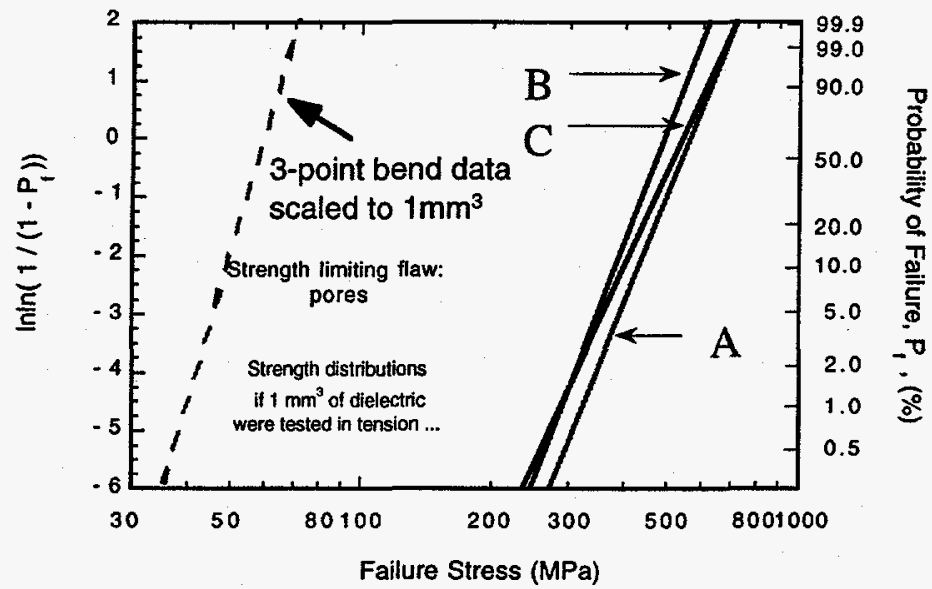

Fig. 5. Predicted strength distributions assuming measured pores were strength limiting flaws. 3-point flexure data were scaled to similar volume for comparison.

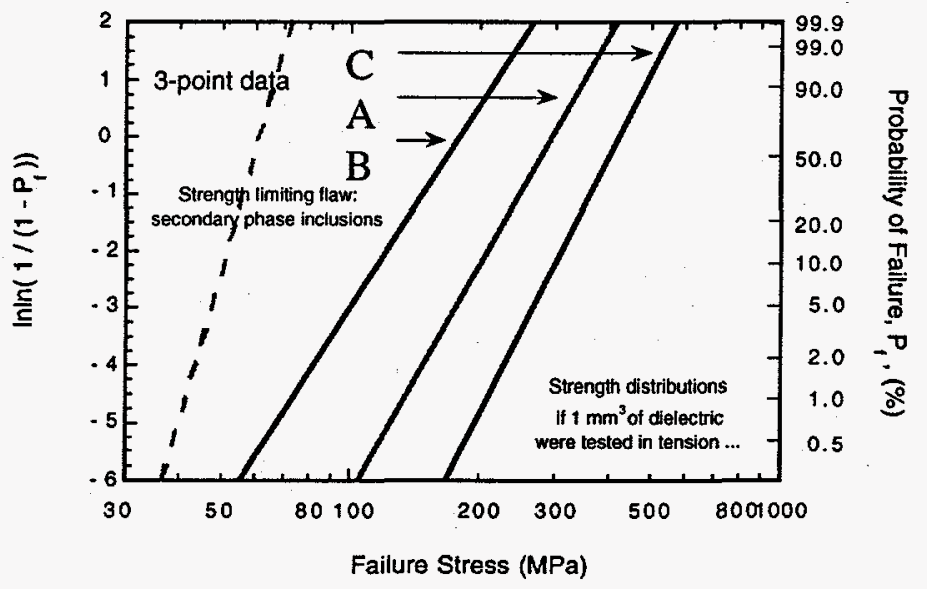

Fig. 6. Predicted strength distributions assuming measured second phase inclusions were strength limiting flaws. 3-point flexure data were scaled to similar volume for comparison. 